\title{
Evaluation of Biological Activity of Two Steroid Derivatives on Glucose Levels Using a Diabetic Model
}

Figueroa-Valverde Lauro ${ }^{1, *}$ (D), Díaz-Cedillo Francisco ${ }^{2}$ (D), Rosas-Nexticapa Marcela ${ }^{3}$ (D) , López-Ramos Maria $^{\text {1, *(D), Mateu-Armad Maria Virginia }}{ }^{3}$ (D), Garcimarrero E. Alejandara ${ }^{4}$ (D), Alvarez-Ramirez Ma. Magdalena $^{3}$ (D) , Ortiz-Ake Yazmin ${ }^{1}$ (D), Cauich-Carrillo Regina ${ }^{1}$ (D)

1 Laboratory of Pharmaco-Chemistry, Faculty of Chemical Biological Sciences, University Autonomous of Campeche, Av. Agustín Melgar s/n, Col Buenavista C.P. 24039 Campeche, Camp., México

2 Escuela Nacional de Ciencias Biológicas del Instituto Politécnico Nacional. Prol. Carpio y Plan de Ayala s/n Col. Santo Tomas, D.F. C.P. 11340, México

3 Facultad de Nutrición, Universidad Veracruzana, Médicos y Odontologos s/n C.P. 91010, Unidad del Bosque Xalapa Veracruz, México

4 Facultad de Medicina, Universidad Veracruzana, Médicos y Odontologos s/n C.P. 91010, Unidad del Bosque Xalapa Veracruz, México

* Correspondence: 1figuero@uacam.mx (F.V.L); maclopez@uacam.mx (R.N.M);

Scopus Author ID 55995915500

Received: 18.08.2020; Revised: 8.09.2020; Accepted: 9.09.2020; Published: 13.09.2020

\begin{abstract}
In this study, three steroid derivatives (compounds 2-4) were prepared from an estrone derivative (compound 1) to evaluate their biological activity on glucose concentration using a diabetic model. Besides, the compounds 1 and 4 were bound to technetium-99m (Tc-99m) via a radioimmunoassay method to evaluate the biodistribution of either compounds 1 and 4 in different organs over time $(15,30,45$, and $60 \mathrm{~min})$. The results showed that both compounds 1 and 4 increase glucose levels compared with either compounds 2 and 3. In addition, other data showed that the biodistribution of the Tc-99m-compound 4 conjugate in all organs was higher compared with Tc-99mcompound 1 complex. In conclusion, compound 4 had greater hypoglycemic effects, and its biodistribution was wider than 1 . The data suggest that amino groups may be important to the hypoglycemic activity of compound 4 , and this could be related to their higher lipophilicity degree compared with compound 1 .
\end{abstract}

Keywords: Steroid; glucose; glibenclamide; metformin; biodistribution.

(C) 2020 by the authors. This article is an open-access article distributed under the terms and conditions of the Creative Commons Attribution (CC BY) license (https://creativecommons.org/licenses/by/4.0/).

\section{Introduction}

Diabetes mellitus is a risk factor in the development of cardiovascular diseases [1-3]; It is noteworthy that several drugs such as sulfonylureas [4], biguanides [5], $\alpha$-glucosidase inhibitors [6], thiazolidinediones [7] have been used for the treatment of this clinical pathology. However, some of these drugs can produce side effects; for example, some studies have reported that the use of glibenclamide can be associated with severe hypoglycemia [8,9] and ventricular arrhythmia in diabetic men [10]. Besides, other reports indicate that metformin can be associated with lactic acidosis in diabetic patients [11]. Other data indicate that rosiglitazone could exert an increased risk of myocardial infarction in type II diabetic patients [12]. Therefore, in the search for new therapeutic alternatives for treatment to diabetes, some compounds have been synthesized; for example, the preparation of an indole derivative from 2,3,5,6-tetrofluoroaniline and pyridine as an aldose reductase inhibitor for the treatment of 
diabetes [13]. Other data showed the synthesis of a series of imidazoline derivatives with biological activity on glucose homeostasis in a rat model of type II diabetes [14]. In addition, a study showed the preparation of a pyran-3,4,5-triol derivative from xylose as a sodiumdependent glucose cotransporter 2 Inhibitor for the Treatment of Type 2 Diabetes [15]. Other reports showed the synthesis of a butanamide analog from 2-Methyl-5-bromobenzoic acid as sodium-dependent glucose cotransporter 1 Inhibitor in a diabetic model [16].

On the other hand, the pharmacological activity of some steroid derivatives on glucose levels has evaluated using some biological models; for example, a study has shown that either dihydroprogesterone or tetrahydroprogesterone can exert a neuroprotective effect against streptozotocin-induced diabetic neuropathy [17]. Besides, other reports have shown the synthesis of a steroid derivative with hypoglycemic activity via glucocorticoid receptor inhibition in a diabetic animal [18]. Other data showed that either 2-methoxyestradiol or 2ethoxyestradiol could decrease the levels of glucose in an animal model [19]. Other studies showed the synthesis of a progesterone-dihydropyrimidine from progesterone, which induces a decrease in glucose levels in diabetic rats [20]. All these data indicate that several compounds have prepared for the treatment of diabetes; however, there are few data on the biological activity exerted by estrone derivatives on glucose concentration; in this way, the aim of this research was to synthesize some estrone derivatives from an estrone analog to evaluate their biological activity on glucose levels using a diabetic model.

\section{Materials and Methods}

\subsection{General.}

The compound 1 (4-(6-fluoro-)-2-nitroestrone-1,5-dinitro-3-azabicyclo-[3.3.1]non-6en-9-yl)butan-2-one) was prepared using a previously method reported (21). In addition, the reagents used in this research were acquired from Sigma-Aldrich Co., Ltd. The melting point for compounds was evaluated on an Electrothermal ( 900 model). Infrared spectra (IR) were evaluated with a Thermo Scientific iSOFT-IR spectrometer. ${ }^{1} \mathrm{H}$ and ${ }^{13} \mathrm{C}$ NMR spectra were recorded using a Varian VXR300/5 FT NMR spectrometer at $300 \mathrm{MHz}$ in $\mathrm{CDCl}_{3}$ using TMS as an internal standard. EIMS spectra were obtained with a Finnigan Trace Gas Chromatography Polaris Q-Spectrometer. Elementary analysis data were acquired from a Perkin Elmer Ser. II CHNS/02400 elemental analyzer.

\subsubsection{Synthesis.}

\section{1-[6-fluoro-3-[2-[(Z)-[(16S)-16-methyl-5-oxapentacyclo[9.7.0.02,8.04,6.012,16] octadeca- 2(8),3,6-trien-15-ylidene]amino]ethyl]-1,5-dinitro-3-azabicyclo[3.3.1]non-6-en-9-yl]pro- pan-2-one (2)}

In a round bottom flask $(10 \mathrm{ml})$, compound 1 (200 $\mathrm{mg}, 0.37 \mathrm{mmol})$, potassium carbonatate $(50 \mathrm{mg}, 0.36 \mathrm{mmol})$, and dimethyl sulfoxide $(5 \mathrm{ml})$ were stirred to room temperature for $72 \mathrm{~h}$. Then, the solvent was evaporated under reduced pressure and following the product was purified via crystallization using the methanol:water $(3: 1)$ system; yielding 52\% of product; m.p. $156-158{ }^{\circ} \mathrm{C}$; IR $\left(V_{\max }, \mathrm{cm}^{-1}\right) 3322,1542,1222$ and 1180: ${ }^{1} \mathrm{H}$ NMR (300 $\left.\mathrm{MHz}, \mathrm{CDCl}_{3}-d\right) \delta_{\mathrm{H}} 1.02(\mathrm{~s}, 3 \mathrm{H}), 1.22-1.86(\mathrm{~m}, 7 \mathrm{H}), 2.08(\mathrm{~s}, 3 \mathrm{H}), 2.10-2.26(\mathrm{~m}, 4 \mathrm{H}), 2.50(\mathrm{~m}$, $1 \mathrm{H}), 2.56(\mathrm{~m}, 1 \mathrm{H}), 2.72(\mathrm{~m}, 1 \mathrm{H}), 2.74(\mathrm{~m}, 1 \mathrm{H}), 2.78-2.80(\mathrm{~m}, 3 \mathrm{H}), 2.84-2.88(\mathrm{~m}, 2 \mathrm{H}), 3.16-$ $3.50(\mathrm{~m}, 4 \mathrm{H}), 3.62-4.32(\mathrm{~m}, 4 \mathrm{H}), 6.32(\mathrm{~m}, 1 \mathrm{H}), 6.40(\mathrm{~m}, 1 \mathrm{H}), 6.56(\mathrm{~m}, 1 \mathrm{H}) \mathrm{ppm} .{ }^{13} \mathrm{C}$ NMR $\left(300 \mathrm{~Hz}, \mathrm{CDCl}_{3}\right) \delta_{\mathrm{C}}: 16.10,21.94,25.76,26.00,29.72,29.84,32.42,32.47,33.90,37.62$, 
37.94, 39.64, 44.56, 50.72, 50.87, 54.22, 54.29, 55.16, 57.95, 89.78, 91.90, 108.92, 109.96, 110.37, 131.44, 135.81, 147.39, 147.67, 155.00, 166.38, 202.90 ppm. EI-MS m/z: 580.26. Anal. Calcd. for $\mathrm{C}_{31} \mathrm{H}_{37} \mathrm{FN}_{4} \mathrm{O}_{6}$ : C, 64.12; H, 6.42; F, 3.27; N, 9.65; O, 16.53. Found: C, 64.10; H, 6.40.

(13S,17Z)-17-[2-(9-acetonyl-6-fluoro-1,5-dinitro-3-azabicyclo[3.3.1]non-6-en-3-yl)ethylimino]-13-methyl-2-nitro-7,8,9,11,12,14,15,16-octahydro-6H-cyclopenta[a]phe-nanthrene-3-carbaldehyde (3)

In a round bottom flask $(10 \mathrm{ml})$, compound $2(200 \mathrm{mg}, 0.34 \mathrm{mmol})$, and dimethyl sulfoxide $(5 \mathrm{ml})$ were stirred to reflux for $24 \mathrm{~h}$. Then, the solvent was evaporated under reduced pressure and following the product was purified via crystallization using the methanol:hexane:water (3:1:1) system; yielding $45 \%$ of product; m.p. $176-178{ }^{\circ} \mathrm{C}$; IR $\left(V_{\max }\right.$, $\left.\mathrm{cm}^{-1}\right) 3322,1722,1540$ and 1182: ${ }^{1} \mathrm{H}$ NMR $\left(300 \mathrm{MHz}, \mathrm{CDCl}_{3}-d\right) \delta_{\mathrm{H}}: 1.02(\mathrm{~s}, 3 \mathrm{H}), 1.22-1.86$ (m, 7H), $2.08(\mathrm{~s}, 3 \mathrm{H}), 2.10-2.26(\mathrm{~m}, 4 \mathrm{H}), 2.50-2.72(\mathrm{~m}, 2 \mathrm{H}), 2.74(\mathrm{~m}, 1 \mathrm{H}), 2.78(\mathrm{~m}, 1 \mathrm{H}), 2.82$ $(\mathrm{m}, 1 \mathrm{H}), 2.84-3.02(\mathrm{~m}, 4 \mathrm{H}), 3.16-3.50(\mathrm{~m}, 4 \mathrm{H}), 3.62-4.32(\mathrm{~m}, 4 \mathrm{H}), 6.40(\mathrm{~m}, 1 \mathrm{H}), 7.80-8.16(\mathrm{~m}$, $2 \mathrm{H}), 10.80(\mathrm{~s}, 1 \mathrm{H}, \mathrm{J}=0.75 \mathrm{~Hz}) \mathrm{ppm} .{ }^{13} \mathrm{C} \mathrm{NMR}\left(300 \mathrm{~Hz}, \mathrm{CDCl}_{3}\right) \delta_{\mathrm{C}}: 16.10,21.94,26.00$, $27.0429 .60,29.72,32.42,32.44,33.92,37.62$, 37.92, 39.64, 44.10, 50.74, 50.87, 54.22, 54.29 , 55.16, 57.95, 89.78, 91.91, 110.34, 123.80, 126.24, 126.49, 146.67, 151.75, 152.24, 155.00, 166.36, 194.24, 202.90 ppm. EI-MS m/z: 639.27. Anal. Calcd. for $\mathrm{C}_{32} \mathrm{H}_{38} \mathrm{FN}_{5} \mathrm{O}_{8}$ : C, 60.08; H, 5.99; F, 2.97; N, 10.95; O, 20.01. Found: C, 60.04; H, 5.96.

1-[1,5-diamino-3-[2-[(Z)-[(13S)-2-amino-3-hydroxy-13-methyl-7,8,9,11,12,14,15,16-octahydro-6H-cyclopenta[a]phenanthren-17-ylidene]amino]ethyl]-6-fluoro-3-aza-bicyclo [3.3.1]non-6-en-9-yl]propan-2-one (4)

In a round bottom flask $(10 \mathrm{ml})$, compound $\mathbf{3}(200 \mathrm{mg}, 0.31 \mathrm{mmol})$, sodium borohydride (60 mg, $1.59 \mathrm{mmol}$ ), and ethanol $(5 \mathrm{ml})$ were stirred to room temperature for $72 \mathrm{~h}$. Then, the solvent was evaporated under reduced pressure and following the product was purified via crystallization using the methanol:water (4:1) system; yielding 67\% of product; m.p. 194-196 ${ }^{\circ} \mathrm{C}$; IR $\left(V_{\max }, \mathrm{cm}^{-1}\right) 3400,3380,3320$ and 1182: ${ }^{1} \mathrm{H}$ NMR $\left(300 \mathrm{MHz}, \mathrm{CDCl}_{3}-d\right) \delta_{\mathrm{H}}: 1.02(\mathrm{~s}, 3 \mathrm{H})$, 1.22-1.86 (m, 7H), 1.98-2.00 (m, 2H), 2.08 (s, 3H), 2.10-2.16 (m, 2H), 2.20-2.22 (m, 2H), 2.26 (m, 1H), $2.36(\mathrm{~m}, 1 \mathrm{H}), 2.44(\mathrm{~m}, 1 \mathrm{H}), 2.52(\mathrm{~m}, 1 \mathrm{H}), 2.54(\mathrm{~m}, 1 \mathrm{H}), 2.74(\mathrm{~m}, 1 \mathrm{H}), 2.78(\mathrm{~m}, 1 \mathrm{H})$, $2.80(\mathrm{~m}, 2 \mathrm{H}), 2.82(\mathrm{~m}, 2 \mathrm{H}), 3.12(\mathrm{~m}, 1 \mathrm{H}), 3.50(\mathrm{~m}, 2 \mathrm{H}), 3.66$ (broad, $7 \mathrm{H}), 5.66(\mathrm{~m}, 1 \mathrm{H}), 6.36-$ $6.82(\mathrm{~m}, 2 \mathrm{H}) \mathrm{ppm} .{ }^{13} \mathrm{C} \mathrm{NMR}\left(300 \mathrm{~Hz}, \mathrm{CDCl}_{3}\right) \delta \mathrm{c}: 16.10,21.96,25.76,26.00,29.72,29.82$, 32.42 , 33.91, 36.04, 37.44, 37.62, 39.64, 43.86, 49.54, 50.84, 54.29, 57.16, 57.43, 58.54, $61.55,62.97,109.26,114.02,116.77,132.71,133.85,134.16,142.83,159.62,166.36$, 209.10 ppm. EI-MS m/z: 537.34. Anal. Calcd. for $\mathrm{C}_{31} \mathrm{H}_{44} \mathrm{FN}_{5} \mathrm{O}_{2}: \mathrm{C}, 69.24 ; \mathrm{H}, 8.25 ; \mathrm{F}, 3.53$; N, 13.02; O, 5.95. Found: C, 69.21; H, 8.22.

\subsection{Pharmacological/biological assays.}

2.2.1. Induction of diabetes.

The animal was injected with alloxan monohydrate dissolved in sterile normal saline at a dose of $150 \mathrm{mg} / \mathrm{kg}$ body wt. intraperitoneally [22].

\subsubsection{Glucose analysis.}

After 2 weeks, rats with moderate diabetes having glycosuria* (indicated by Benedict's qualitative test) and hyperglycemia (i.e., with a blood glucose $\geq 200 \mathrm{mg} / \mathrm{dl}$ ) were used for the experiment [21]. 
* Blood glucose was determined from tail blood with a rapid glucose analyzer (Accutrend Sensor Comfort; Roche, U.S.A.) every 48 h. The rats were divided into sixteen groups after the induction of diabetes. Six rats were used in each group (90 diabetic surviving rats, six normal rats) as follows.

\subsection{Experimental design (I).}

Group 1: Normal rats were given $2 \mathrm{ml}$ of normal saline.

Group 2: Diabetic control rats given $2 \mathrm{ml}$ of normal saline.

Group 3 Diabetic rats were given an aqueous solution of glibenclamide ${ }^{\phi}(600 \mu \mathrm{g} / \mathrm{kg}$ body mass $)$ daily with an intragastric tube for 30 days.

Group 4: Diabetic rats given an aqueous solution of metformin ${ }^{\varpi}(350 \mathrm{mg} / \mathrm{kg}$ body mass) daily had an intragastric tube for 30 days.

Group 5: Diabetic rats were given an aqueous solution of compound $1(20 \mathrm{mg} / \mathrm{ml})$ daily with an intragastric tube for 30 days.

Group 6: Diabetic rats were given an aqueous solution of compound $2(20 \mathrm{mg} / \mathrm{ml})$ daily with an intragastric tube for 30 days.

Group 7: Diabetic rats were given an aqueous solution of compound $3(20 \mathrm{mg} / \mathrm{ml})$ daily with an intragastric tube for 30 days.

Group 8: Diabetic rats were given an aqueous solution of compound 4 (20 mg/ml) daily with an intragastric tube for 30 days.

${ }^{\phi, \varpi}$ Dose administered of either glibenclamide or metformin was determined using a previous method reported [22].

\subsection{Experimental design (II).}

Group 9: Diabetic rats were given an aqueous solution of compound $1(2.5 \mathrm{mg} / \mathrm{ml})$ daily with an intragastric tube for 30 days.

Group 10: Diabetic rats were given an aqueous solution of compound $1(5 \mathrm{mg} / \mathrm{ml})$ daily with an intragastric tube for 30 days.

Group 11: Diabetic rats were given an aqueous solution of compound $1(15 \mathrm{mg} / \mathrm{ml})$ daily with an intragastric tube for 30 days.

Group 12: Diabetic rats were given an aqueous solution of compound $1((20 \mathrm{mg} / \mathrm{ml})$ daily with an intragastric tube for 30 days.

\subsection{Experimental design (III).}

Group 13: Diabetic rats were given an aqueous solution of compound $4(2.5 \mathrm{mg} / \mathrm{ml})$ daily with an intragastric tube for 30 days.

Group 14: Diabetic rats were given an aqueous solution of compound $4(5 \mathrm{mg} / \mathrm{ml})$ daily with an intragastric tube for 30 days.

Group 15: Diabetic rats were given an aqueous solution of compound 4 (15 mg/ml) daily with an intragastric tube for 30 days.

Group 16: Diabetic rats were given an aqueous solution of compound $4(20 \mathrm{mg} / \mathrm{ml})$ daily with an intragastric tube for 30 days.

${ }^{\phi, \varpi}$ Dose administered of either glibenclamide or metformin was determinated using a previous method reported [22]. 


\subsection{Statistical analysis.}

The obtained values are expressed as average \pm SE. The results were put under an analysis of variance (ANOVA) with the Bonferroni correction factor using the SPSS 12.0 program [23]. The differences were considered significant when $p$ was equal to or smaller than 0.05 .

\subsection{Radiochemical analysis.}

The compounds 1 and 4 were bound to Tc-99m using previously methods reported [22]. In this way, a solution of either compounds 1 or $4(20 \mathrm{mg})$ in ethanol $(1.0 \mathrm{ml})$ was adjusted to $\mathrm{pH} 7.0$ using $0.1 \mathrm{M} \mathrm{NaOH}$. The mixture was then added to another freshly prepared solution $(75 \mathrm{ml})$ of stannous chloride $(2 \mathrm{mg} / \mathrm{ml}$ in $0.1 \mathrm{M} \mathrm{HCl})$, and following the $\mathrm{pH}$ was readjusted to 7.0. Then, $2 \mathrm{ml}$ of a Tc-99m pertechnetate solution eluted from a sterile $99 \mathrm{Mo}-99 \mathrm{~m}-\mathrm{Tc}$ shielded generator was added to the mixture solution.

\subsection{Quality control.}

The labeling efficiencies with Tc-99m were evaluated via a chromatographic analysis on Silica-gel 60 F254 plate using the acetonitrile:water (4:1) system. The plates were counted by images in a gamma camera equipped with a high-resolution collimator with a digital computer (VP450). In addition, reference factor value was evaluated using as control Tc-99m pertechnetate and the hydrolyzed Tc-99m colloid. The purities of the Tc-99m-conjugates was evaluated by paper electrophoresis. The paper strips were run at a constant voltage of $600 \mathrm{~V}$ for 30 min using a buffer solution $(0.1 \mathrm{M}, \mathrm{pH}$ 7.4). The paper strips were counted by images in a gamma camera equipped with a high-resolution collimator with a digital computer. The movement was determined relative to Tc-99m pertechnetate and hydrolyzed Tc-99m colloid [24].

\subsection{Pharmacocinetic analyses.}

Each diabetic animal received $0.3 \mathrm{ml}$ of either Tc-99m-compound 1 conjugate or Tc$99 \mathrm{~m}$-compound 4 complex $(200 \mu \mathrm{Ci}, 1.3 \mathrm{mg})$ via tail vein administration. It is noteworthy that sequential scintigrams were taken at 15,30, 45, and $60 \mathrm{~min}$ with a gamma camera equipped with a high-resolution collimator with a digital computer. Then, the diabetic rats were sacrificed, and the organs were removed, and the radioactivity was counted by images in a gamma camera equipped with a high-resolution collimator with a digital computer. Beside, percentages of the injected dose per organ were determined by comparison of tissue radioactivity concentration with the total radioactivity. Following, the blood (ml) in the heart was collected to evaluate the radioactivity with the same equip.

\section{Results and Discussion}

Several compounds with hypoglycemic activity have been synthesized; however, several protocols use some reagents which require special conditions. In this research, some steroid derivatives were prepared to evaluate their biological activity on glucose levels using a diabetic model. The first stage was achieved as follows: 


\subsection{Chemistry.}

\subsubsection{Preparation of an ether derivative.}

Several reagents such as $\mathrm{Me}_{3} \mathrm{SiCN}, \mathrm{K}_{2} \mathrm{CO}_{3} /$ acetone, tetrahydrofuran/lithium/aluminum hydride, $\mathrm{Me}_{3} \mathrm{SiCl}, \mathrm{K}_{3} \mathrm{PO}_{4} / \mathrm{DMF}$, ethyl cinnamate have used for the preparation of ether derivatives [25]. In this research, a previous method reported [26] was used to preparation of compound 2; in this way, compound 1 reacted with dimethyl sulfoxide in middle conditions to form 2 (Figure 1).

The ${ }^{1} \mathrm{H}$ NMR spectrum from 2 showed several signals at $1.02 \mathrm{ppm}$ for methyl group bound to steroid nucleus; at $2.08 \mathrm{ppm}$ for methyl group linked to ketone group; at 1.22-1.86, $2.10-2.26,2.56,2.78-2.80,6.32$ and 6.56 ppm for steroid moiety; at 2.50, 2.72, 3.62-4.32 and $6.40 \mathrm{ppm}$ for 3-Aza-bicyclo[3.3.1]non-6-ene fragment; at 2.74 and 2.84-2.88 ppm for methylene groups bound to both 3-Aza-bicyclo[3.3.1]non-6-ene fragment and ketone group; at 3.16-3.50 ppm for methylene groups bound to both amino and imino groups. ${ }^{13} \mathrm{C}$ NMR spectra showed chemical shifts at $16.10 \mathrm{ppm}$ dor methyl group bound to steroid nucleus; at $29.72 \mathrm{ppm}$ for methyl group linked to ketone group; at 21.94-26.00, 29.84-32.42, 33.90-37.62, 29.6444.56, 108.92-109.96 and 131.44-147.67 ppm for steroid moiety; at 32.47, 50.72, 55.16-110.37 and $155.00 \mathrm{ppm}$ for 3-Aza-bicyclo[3.3.1]non-6-ene fragment; at 37.94 methylene groups bound to both 3-Aza-bicyclo[3.3.1]non-6-ene fragment and ketone group; at 50.87-54.22 ppm for methylene groups linked to both amino and imino groups; at $166.36 \mathrm{ppm}$ for imino group; at $209.90 \mathrm{ppm}$ for ketone group. Besides, the mass spectrum from 2 showed a molecular ion $(\mathrm{m} / \mathrm{z}) 580.26$.

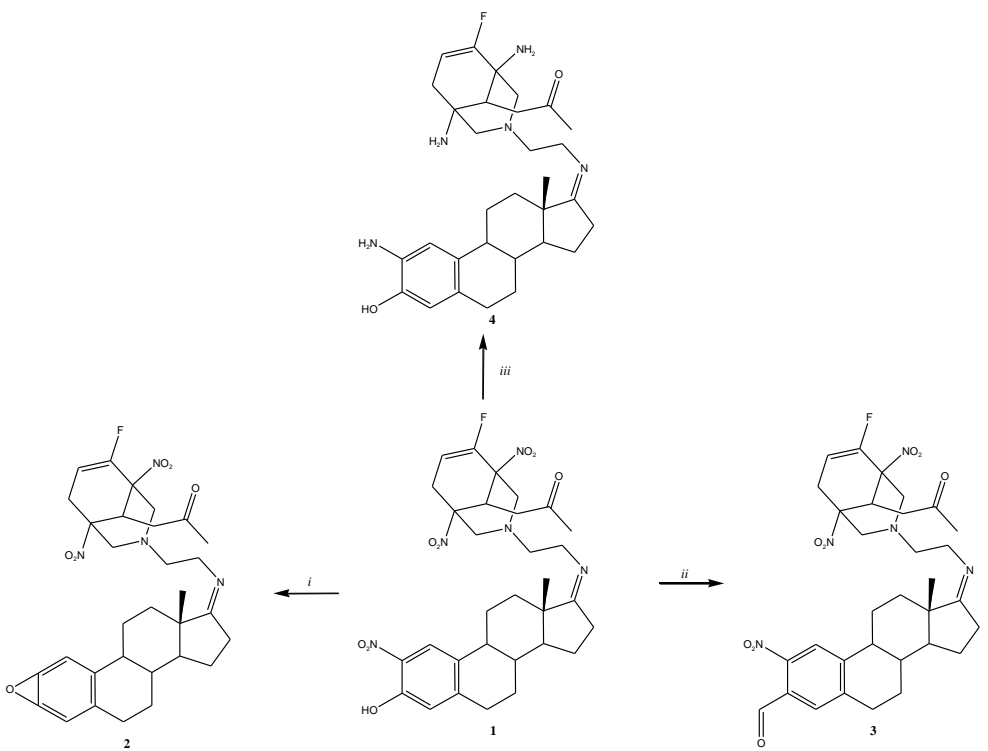

Figure 1. Sinthesis of steroid derivatives (2-4). Reagents and conditions; $i i=$ dimethyl sulfoxide, $\mathrm{K}_{2} \mathrm{CO}_{3}$, room temperature, $72 \mathrm{~h} ; i i=$ dimethyl sulfoxide, reflux $24 \mathrm{~h} ; i i i=$ sodium borohydride/Zn, room temperature, $48 \mathrm{~h}$.

\subsubsection{Synthesis of an aldehyde-steroid derivative.}

There are several reports for the preparation of some aldehyde derivatives using some reagents such as chromium(VI), palladium, rhodium/ruthenium, and hydrogen peroxide. However, these reagents require special conditions and may produce toxic effects by the generation of some products involved in the reaction mixtures [27]. Analyzing these data and other reports for the preparation of some aldehyde derivatives in the presence of dimethyl 
sulfoxide [28]; in this study, an aldehyde-steroid derivative was prepared via reaction of compound 2 with dimethyl sulfoxide (Figure 1). The ${ }^{1} \mathrm{H}$ NMR spectrum from 3 showed several signals at $1.02 \mathrm{ppm}$ for methyl group bound to steroid nucleus; at $2.08 \mathrm{ppm}$ for methyl group linked to ketone group; at 1.22-1.86, 2.10-2.26, 2.78, 2.84-3.02 and 780-8.16 ppm for steroid moiety; at 2.50 and 3.62-6.40 ppm for 3-Aza-bicyclo[3.3.1]non-6-ene fragment; at 2.74 and $2.82 \mathrm{ppm}$ for methylene groups bound to both 3-Aza-bicyclo[3.3.1]non-6-ene fragment and ketone group; at 3.16-3.50 ppm for methylene groups bound to both amino and imino groups; at $10.80 \mathrm{ppm}$ for aldehyde group. ${ }^{13} \mathrm{C}$ NMR spectra showed chemical shifts at $16.10 \mathrm{ppm}$ dor methyl group bound to steroid nucleus; at $29.72 \mathrm{ppm}$ for methyl group linked to ketone group; at $21.94-29.60,32.42,33.92-37.62,39.64-44.10,54.29$ and 123.80-152.24 ppm for steroid moiety; at 32.44, 50.74, 55.16-110.34 and $155.00 \mathrm{ppm}$ for 3-Aza-bicyclo[3.3.1]non-6-ene fragment; at $37.92 \mathrm{ppm}$ for methylene groups bound to both 3-Aza-bicyclo[3.3.1]non-6-ene fragment and ketone group; at 50.87-54.22 ppm for methylene groups bound to amino and imino groups; at $166.36 \mathrm{ppm}$ for imino group; at $194.24 \mathrm{ppm}$ for aldehyde group; at 202.90 ppm for ketone group. In addition, the mass spectrum from 3 showed a molecular ion $(\mathrm{m} / \mathrm{z})$ 639.27 .

\subsubsection{Reduction of nitro groups.}

Several protocols have used to reduction of nitro groups using some reagents such as $\mathrm{TiO}_{2}$ [29], $\mathrm{CuSO}_{4}$ [30], phthalocyanine-cobalt(I) anion [31], Iron(II) sulfate [32], palladium [33]. In this investigation, compound 4 was prepared via the reduction of nitro groups in the presence of sodium borohydride (Figure 1). The ${ }^{1} \mathrm{H}$ NMR spectrum from 4 showed several signals at $1.02 \mathrm{ppm}$ for methyl group bound to steroid nucleus; at $2.08 \mathrm{ppm}$ for methyl group linked to ketone group; at 1.22-1.86, 2.10-2.16, 2.26, 2.52, 2.74, 2.80 and 6.36-6.82 ppm for steroid moiety; at 1.98-2.00, 2.20-2.22, 2.36, 2.78, 3.12 and 5.66 ppm for 3-Azabicyclo[3.3.1]non-6-ene fragment; at 2.44 and $2.54 \mathrm{ppm}$ for methylene groups bound to both 3-Aza-bicyclo[3.3.1]non-6-ene fragment and ketone group; at 2.82 and $3.50 \mathrm{ppm}$ for methylene groups bound to amino and imino groups; at $3.66 \mathrm{ppm}$ for either hydroxyl and amino groups. ${ }^{13} \mathrm{C}$ NMR spectra showed chemical shifts at $16.10 \mathrm{ppm}$ dor methyl group bound to steroid nucleus; at 29.72 ppm for methyl group linked to ketone group; at 21.96-26.00, 29.82-33.91, 37.62-43.86, 54.29 and 114.02-142.83 ppm for steroid moiety; at 36.04, 49.54, 57.16, 58.54.109.26 and 159.62 ppm for 3-Aza-bicyclo[3.3.1]non-6-ene fragment; at $37.44 \mathrm{ppm}$ for methylene groups bound to both 3-Aza-bicyclo[3.3.1]non-6-ene fragment and ketone group; at 50.84 and $57.43 \mathrm{ppm}$ for methylene groups bound to both amino and imino groups; at 166.36 ppm for imino group; at $209.10 \mathrm{ppm}$ for ketone group. Finally, the mass spectrum from 4 showed a molecular ion $(\mathrm{m} / \mathrm{z}) 537.34$.

\subsection{Pharmacology/biology.}

\subsubsection{General methods.}

All experimental procedures and protocols used in this investigation were reviewed and approved by the Animal Care and Use Committee of Universidad Autonoma de Campeche (UAC) and were in accordance with the Guide for the Care and Use of Laboratory Animals(Washington, DC: National Academy Press, 1996) (30). Female rats (Wistar; weighing 200-250 g) were obtained from UAC. 


\subsubsection{Glucose analysis.}

The biological activity exerted by the compounds 1 to 4 on glucose levels was evaluated using a diabetic animal model. In this way, alloxan was administered to male rats to induce diabetes; it is noteworthy that alloxan reagent can cause a massive reduction in insulin release, via the destruction of $\beta$-cells of the islets of Langerhans, which resulting as an indirect increase in the glucose levels [34].

The results showed that both compounds 1 and 4 lower glucose levels at doses of 20 $\mathrm{mg} / \mathrm{ml}$ compared to compounds 2 and 3 (Figure 2). These data indicate that the biological activity exerted by compounds 1 and 4 may depend on the functional groups involved in its chemical structure.

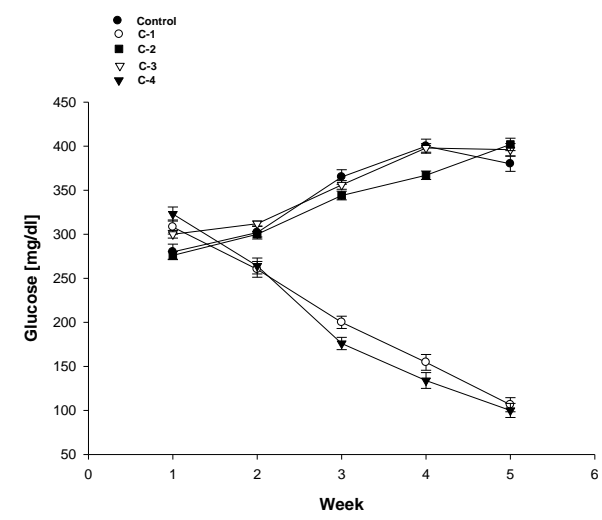

Figure 2. Biological activity was exerted by both compound 1 (C-1) and compound 4 (C-4) on glucose concentration in a diabetic rat model. The results showed that either compounds 1 or 4 significantly decreases $(p=0.05)$ the blood glucose concentration at a dose of $20 \mathrm{mg} / \mathrm{ml}$ compared with both compounds 2 or 3 . The effects are expressed as mean \pm S.E. $n=6$.

However, it is important to mention that alternative experiments were carried out to find the minimum effective dose by which these compounds could lower the glucose concentration. The results showed that compound 1 significantly decrease the glucose concentration at a dose of $20 \mathrm{mg} / \mathrm{dl}$ in a dose-dependent manner (Figure 3); however, compound 4 significantly decrease the glucose levels at a dose of 10 and $20 \mathrm{mg} / \mathrm{dl}$. This phenomenon could depend on effect exerted of amino groups involved in the chemical structure of 4 (Figure 4).

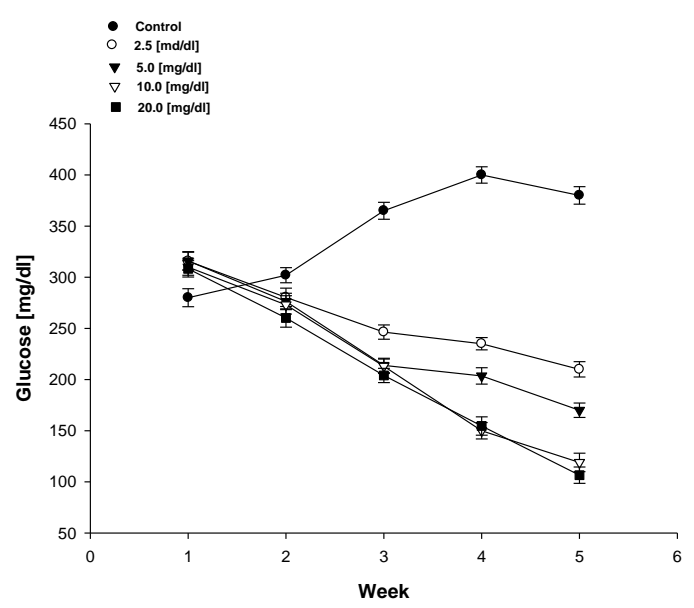

Figure 3. Effects exerted by compound 1 on glucose levels in a diabetic rat model. The results showed that 1 significantly decrease $(\mathrm{p}=0.05)$ in a dose-dependent manner, the blood glucose concentration. The effects are expressed as mean \pm S.E. $\mathrm{n}=6$. 


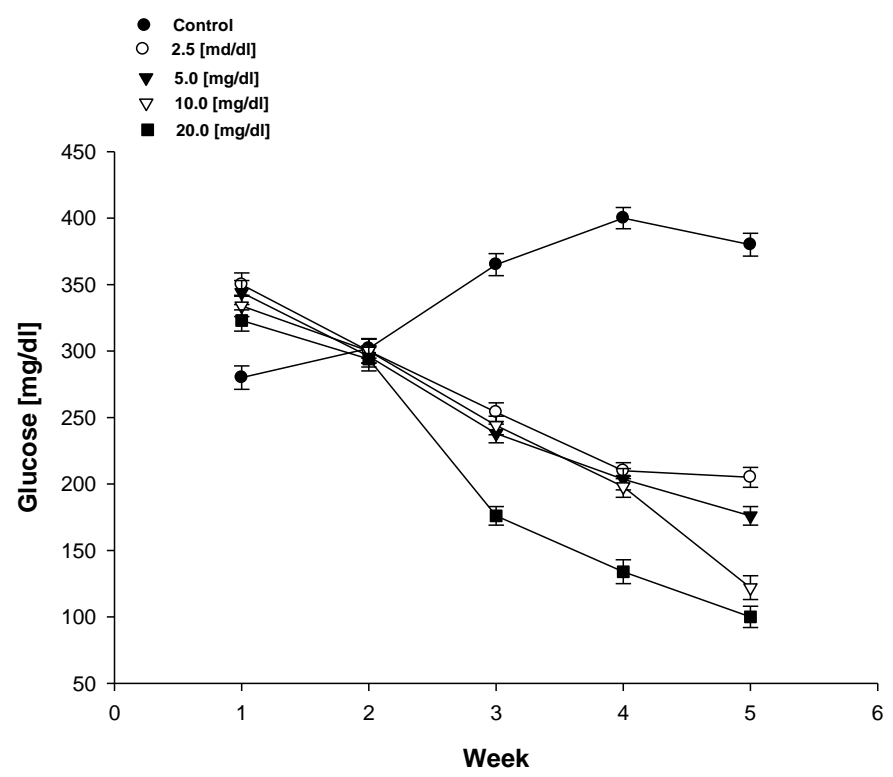

Figure 4. Biological activity induced by compound 4 on glucose levels in a diabetic rat model. The results showed that 4 significantly decrease $(\mathrm{p}=0.05)$ in a dose-dependent manner, the blood glucose concentration. The effects are expressed as mean \pm S.E. $n=6$.

On the other hand, the biological activity exerted by metformin (insulin receptor activator) [35] and glibenclamide (potassium-channel inhibitor) [36] on glucose concentration was evaluated. The results showed that both metformin and glibenclamide decreases glucose levels (Figure 5).

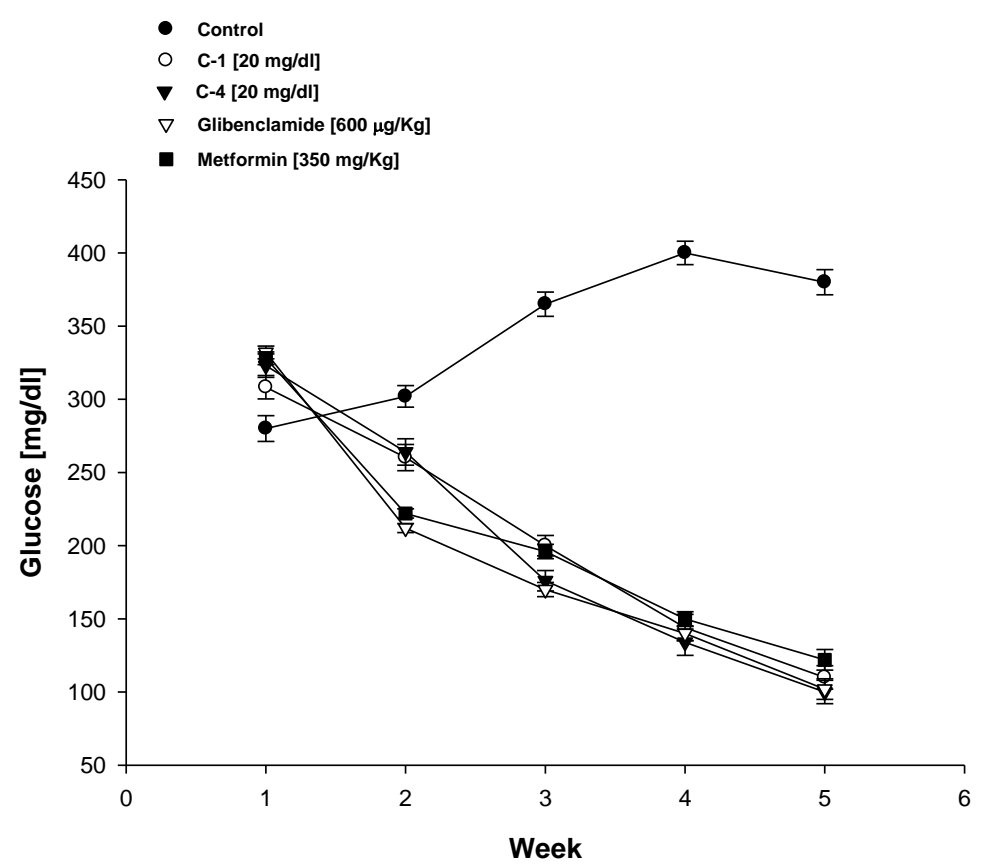

Figure 5. Effects are exerted by the compounds 1, 4, glibenclamide, and metformin on glucose levels in a diabetic rat model. The results showed that compounds 1,4 , glibenclamide and metformin significantly decrease $(\mathrm{p}=0.05)$ in a time-dependent manner in the blood glucose levels.

The effects are expressed as mean \pm S.E. $n=6$.

It is noteworthy that these effects were compared with biological activity exerted by either compounds 1 or 4 . The data indicate that the effect exerted by either compounds 1 and 4 was similar to biological activity induced by metformin on glucose concentration. This 
phenomenon could also be associated with some pharmacokinetic parameters involved in the biological activity of compounds 1 or 4 on glucose concentration. To evaluate this hypothesis, this research was evaluated the biodistribution of either compound 1 or 4 using a previously radioimmunoassay method reported [22]. In this way, both compounds 1 and 4 were bound to Tc-99m with the conventional stannous chloride method; it is important to mention that steroid conjugates were excellent chelating agents, via the hydroxyl groups binding to Tc-99m.

On the other hand, the biodistribution of either Tc-99m-compound 1 and Tc-99mcompound 4 conjugates as a consequence of increases in time $(15,30,45$, and $60 \mathrm{~min})$ was evaluated. The results showed that the biodistribution of the Tc-99m-Compound 4 conjugate was significantly higher in each organ evaluated compared with the values for the Tc-99mcompound 1 complex (Figure 6, Tables 1 and 2).
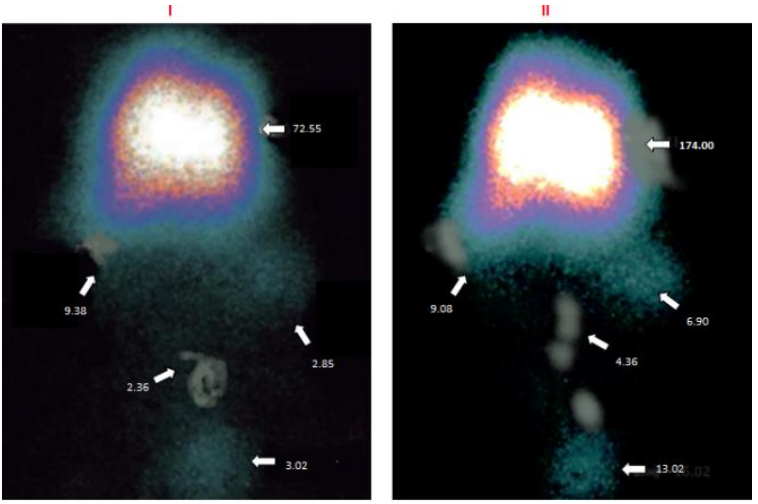

Figure 6. Scintigrams $(\mu \mathrm{Ci})$ were taken $60 \mathrm{~min}$ after the administration of the Tc-99m-steroid derivatives. The Tc-99-compound 1 conjugate (I) shows different values in each organ compared with Tc-99-compound 4 complex. The paper strips were counted by images in a gamma camera equipped with a high-resolution collimator with a digital computer.

Table 1. Biodistribution of Tc-99m-compound $1(\mu \mathrm{Ci})$. Each value is mean \pm S.E. $n=6$.

\begin{tabular}{l|l|l|l|l} 
Organ & $\mathbf{1 5}$ min & $\mathbf{3 0}$ min & $\mathbf{4 5}$ min & $\mathbf{6 0}$ min \\
\hline Brain & $69.02 \pm 2.67$ & $70.28 \pm 2.24$ & $71.34 \pm 2.34$ & $72.55 \pm 2.68$ \\
Spleen & $10.09 \pm 2.98$ & $10.26 \pm 2.45$ & $9.56 \pm 2.12$ & $10.31 \pm 2.14$ \\
Stomach & $9.02 \pm 1.68$ & $9.09 \pm 1.53$ & $9.22 \pm 1.87$ & $9.38 \pm 2.34$ \\
Intestine & $3.16 \pm 1.28$ & $2.96 \pm 2.12$ & $2.87 \pm 1.24$ & $2.36 \pm 1.24$ \\
Liver & $2.35 \pm 1.56$ & $2.50 \pm 1.44$ & $2.42 \pm 1.76$ & $2.85 \pm 1.34$ \\
Kidmey & $2.04 \pm 1.62$ & $3.22 \pm 1.54$ & $2.82 \pm 1.34$ & $3.02 \pm 1.28$ \\
Gonads & $4.10 \pm 1.44$ & $3.88 \pm 1.42$ & $3.66 \pm 1.55$ & $3.02 \pm 1.44$ \\
Blood & $2.55 \pm 1.45$ & $2.12 \pm 1.06$ & $1.66 \pm 1.45$ & $1.43 \pm 1.34$
\end{tabular}

Table 2. Biodistribution of Tc-99m-compound $\mathbf{1}(\mu \mathrm{Ci})$. Each value is mean \pm S.E. $n=6$.

\begin{tabular}{l|l|l|l|l} 
Organ & $\mathbf{1 5} \mathbf{~}$ in & $\mathbf{3 0} \mathbf{~}$ in & $\mathbf{4 5} \mathbf{~ m i n}$ & $\mathbf{6 0} \mathbf{~ m i n}$ \\
\hline Brain & $190.02 \pm 1.89$ & $178.09 \pm 2.22$ & $170.00 \pm 2.28$ & $174.00 \pm 2.45$ \\
Spleen & $12.45 \pm 2.43$ & $12.26 \pm 2.67$ & $11.00 \pm 2.02$ & $10.98 \pm 2.14$ \\
Stomach & $10.90 \pm 1.68$ & $10.56 \pm 2.22$ & $9.28 \pm 1.67$ & $9.08 \pm 1.22$ \\
Intestine & $5.16 \pm 2.02$ & $6.06 \pm 1.67$ & $5.66 \pm 1.24$ & $4.36 \pm 1.67$ \\
Liver & $7.76 \pm 1.86$ & $7.70 \pm 1.44$ & $6.98 \pm 1.36$ & $6.90 \pm 1.34$ \\
Kidmey & $3.04 \pm 1.44$ & $4.28 \pm 1.14$ & $3.82 \pm 1.15$ & $3.22 \pm 1.27$ \\
Gonads & $15.05 \pm 1.56$ & $15.44 \pm 1.42$ & $14.32 \pm 1.12$ & $13.02 \pm 1.22$ \\
Blood & $3.98 \pm 1.22$ & $3.12 \pm 1.35$ & $2.22 \pm 1.45$ & $1.89 \pm 1.14$
\end{tabular}

Table 3. Lipophilicity degree of compounds 1 and 4.

\begin{tabular}{c|c|c} 
Log P method & Compound 1 & Compound 4 \\
\hline iLOGP & 3.08 & 2.96 \\
XLOGP3 & 3.80 & 1.11 \\
WLOGP & 4.84 & 3.88 \\
MLOGP & 1.21 & 2.18 \\
SILICOS-IT & -0.38 & 3.90 \\
Consensus & 2.51 & 2.81
\end{tabular}


The results indicate the following: 1) both compounds 1 or 4 were distributed to all tissues; 2) the concentration of either compounds 1 or 4 in the brain was higher than in other organs. This phenomenon may be conditioned by the interaction between the compounds 1 or 4 with some endogenous substances involved in the brain; 3) differences in the biodistribution of either compound 1 or 4 could depend on their lipophilicity degree. Analyzing these data, in this study was carried out a theoretical test to evaluate the lipophilicity degree of either compound 1 or 4 using SwissADME software. The results showed that the lipophilicity degree was higher for 4 compared with compound 1 (Table 3 ).

\section{Conclusions}

Compound 4 exerts a higher hypoglycemic activity, and its biodistribution was greater compared with compound 1. These data suggest that amino groups involved in the chemical structure of 4 may be important to their hypoglycemic, and this phenomenon could be related to higher lipophilicity in comparison with 4.

\section{Funding}

This research received no external funding.

\section{Acknowledgments}

To Benjamin Valverde and Raquel Anzurez, for your unconditional support on this manuscript.

\section{Conflicts of Interest}

The authors declare no conflict of interest.

\section{References}

1. Petrie, M.; Verma, S.; Docherty, K.; Inzucchi, S.; Anand, I.; Belohlavek, J.; Böhm, M.; Chiang, C.; Chopra, V.; de Boer, R. Effect of dapagliflozin on worsening heart failure and cardiovascular death in patients with heart failure with and without diabetes. Journal of the American Medical Association 2020, 323, 1353-1368, https://doi.org/10.1001/jama.2020.1906.

2. Francesco, C.; Peter, J.; Victor, A.; Clifford, J.; Antonio, C. 2019 ESC Guidelines on diabetes, pre-diabetes, and cardiovascular diseases developed in collaboration with the EASD: The Task Force for diabetes, prediabetes, and cardiovascular diseases of the European Society of Cardiology (ESC) and the European Association for the Study of Diabetes (EASD). European Heart Journal 2020, 41, 255-323, https://doi.org/10.1093/eurheartj/ehz486.

3. Chiang, C.; Ueng, K.; Chao, T.; Lin, T.; Wu, Y.; Wang, K.; Sung, S.; Yeh, H.; Li, Y.; Liu, P.; Chang, K.; Shyu, K.; Huang, J.; Tsai, C.; Hung, H.; Liu, M.; Chao, T.; Cheng, S.; Cheng, H.; Chu, P.; Yin, W.; Wu, Y.; Chen, W.; Lai, W.; Lin, S.; Yeh, S.; Hwang, J. Consensus of Taiwan Society of Cardiology on the pharmacological management of patients with type 2 diabetes and cardiovascular diseases. Journal of the Chinese Medical Association 2020, 83, 587-621, https://doi.org/10.1097/JCMA.0000000000000359.

4. Buse, J.; Wexler, D.; Tsapas, A.; Rossing, P.; Mingrone, G.; Mathieu, C.; Davies, M. 2019 Update to: Management of Hyperglycemia in Type 2 Diabetes, 2018. A Consensus Report by the American Diabetes Association (ADA) and the European Association for the Study of Diabetes (EASD). Diabetes Care 2020, 43, https://doi.org/10.2337/dci19-0066.

5. Cusi, K.; DeFronzo, R. Metformin: a review of its metabolic effects. Diabetes Reviews 1998, 6, 89-131.

6. Gao, F.; Ma, X.; Peng, J.; Lu, J.; Zhu, W.; Zhou J. The Effect of Acarbose on Glycemic Variability in Patients with Type 2 Diabetes Mellitus Using Premixed Insulin Compared to Metformin (AIM): An Open-Label Randomized Trial. Diabetes Technology y Therapeutics 2020, 22, 256-254, https://doi.org/10.1089/dia.2019.0290.

7. Yen, F.; Yang, Y.; Hwu, C.; Wei, J.; Huang, Y.; Hou, M.; Hsu C. Liver-related long-term outcomes of thiazolidinedione use in persons with type 2 diabetes. Liver International 2020, 40, https://doi.org/10.1111/liv.14385. 
8. Shorr, R.; Ray, W.; Daugherty, J.; Griffin, M. Incidence and risk factors for serious hypoglycemia in older persons using insulin or sulfonylureas. Archiv. Int. Med. 1997, 157, 1681-1686, https://doi.org/10.1001/archinte.1997.00440360095010.

9. Lai, J.; Wang, M.; Wu, C.; Huang, Y.; Lu, C.; Liou, J. Risk of severe hypoglycemic events from amiodaronesulfonylureas interactions: A population-based nested case-control study. Pharmacoepidemiology y Drug Safety 2020, 28, https://doi.org/10.1002/pds.5034.

10. Dhopeshwarkar, N.; Brensinger, C.; Bilker, W.; Soprano, S.; Flory, J.; Dawwas, G.; Leonard, C. Risk of sudden cardiac arrest and ventricular arrhythmia with sulfonylureas: An experience with conceptual replication in two independent populations. Scientific Reports 2020, 10, https://doi.org/10.1038/s41598-02066668-5.

11. Gan, S.; Barr, J.; Arieff, A.; Pearl, R. Biguanide-associated lactic acidosis: case report and review of the literature. Archives of Internal Medicine 1992, 152, 2333-6.

12. Singh, S.; Loke, Y.; Furberg, C. Long-term risk of cardiovascular events with rosiglitazone: a meta-analysis Journal of the American Medical Association 2007, 298, 1189-1195, https://doi.org/10.1001/jama.298.10.1189.

13. Van, M.; Jones, M.; Gunn, D.; Geraci, L.; Jones, J.; Sawicki, D.; Mitschler, A. Discovery of 3-[(4, 5, 7trifluorobenzothiazol-2-yl) methyl] indole-N-acetic acid (lidorestat) and congeners as highly potent and selective inhibitors of aldose reductase for treatment of chronic diabetic complications. Journal of medicinal chemistry 2005, 48, 3141-3152, https://doi.org/10.1021/jm0492094.

14. Rondu, F.; Le Bihan, G.; Wang, X.; Lamouri, A.; Touboul, E.; Dive, G.; Manechez, D. Design and synthesis of imidazoline derivatives active on glucose homeostasis in a rat model of type II diabetes. 1. Synthesis and biological activities of N-benzyl-N '-(arylalkyl)- 2-(4 ', 5 '-dihydro-1 'H-imidazol-2 '-yl) piperazines. Journal of medicinal chemistry 1997, 40, 3793-3803, https://doi.org/10.1021/jm9608624.

15. Goodwin, N.; Mabon, R.; Harrison, B.; Shadoan, M.; Almstead, Z.; Xie, Y.; Mseeh, F. Novel L-xylose derivatives as selective sodium-dependent glucose cotransporter 2 (SGLT2) inhibitors for the treatment of type 2 diabetes. Journal of medicinal chemistry 2009, 52, 6201-6204, https://doi.org/10.1021/jm900951n.

16. Goodwin, N.; Ding, Z.; Harrison, B.; Strobel, E.; Harris, A.; Smith, M.; Diaz, D. Discovery of LX2761, a sodium-dependent glucose cotransporter 1 (SGLT1) inhibitor restricted to the intestinal lumen, for the treatment of diabetes. Journal of medicinal chemistry 2017, 60, 710-721, https://doi.org/10.1021/acs.jmedchem.6b01541.

17. Leonelli, E.; Bianchi, R.; Cavaletti, G.; Caruso, D.; Crippa, D.; Garcia, L.; Melcangi, R. Progesterone and its derivatives are neuroprotective agents in experimental diabetic neuropathy: a multimodal analysis. Neuroscience 2007, 144, 1293-1304, https://doi.org/10.1016/j.neuroscience.2006.11.014.

18. Von-Geldern, T.; Tu, N.; Kym, P.; Link, J.; Jae, H.; Lai, C.; Grynfarb, M. Liver-selective glucocorticoid antagonists: a novel treatment for type 2 diabetes. Journal of medicinal chemistry 2004, 47, 4213-4230, https://doi.org/10.1021/jm0400045.

19. X. Zhang, Y. Jia, E. Jackson, S. Tofovic, 2-Methoxyestradiol and 2-ethoxyestradiol retard the progression of renal disease in aged, obese, diabetic ZSF1 rats. Journal of cardiovascular pharmacology 2007, 49, 5663, https://doi.org/10.1097/FJC.0b013e31802cb88e.

20. Figueroa-Valverde, L.; Díaz-Cedillo, F.; López-Ramos, M.; Garcia-Cervera, E. Activity induced by two Steroid-Dihydropyrimidine derivatives on Glucose levels in a Diabetic Rat Model. Relationship between descriptors $\log \mathrm{P}$ and $\pi$ and its Antidiabetic activity. International Journal of PharmTech Research 2010, 2 , 2075-2080.

21. Figueroa-Valverde, L.; Diaz Cedillo, F.; Rosas-Nexticapa, M.; Mateu-Armand, V.; García-Cervera, E.; Pool Gómez, E.; HauHeredia, L.; Lopez-Ramos, M.; Alfonso-Jimenez, A. Cabrera-Tuz, J. Design and synthesis of two 3-aza-bicyclo[3,3,1]nonane-estrone derivatives. Heterocyclic Letters 2019, 9, https://doi.org/10.22034/AJGC.2018.144189.1093.

22. Figueroa-Valverde, L.; Diaz-Cedillo, F.; Lopez-Ramos, M.; Garcia-Cervera, E.; Pool-Gomez, E.; CardenaArredondo, C.; Ancona-Leon, G. Glibenclamide-pregnenolone derivative has greater hypoglycemic effects and biodistribution than glibenclamide-oh in alloxan-rats. Biomedical Papers 2012, 156, 122-127, http://dx.doi.org/10.5507/bp.2012.028.

23. Hocht, C.; Opezzo, L.; Gorzalczany, S.; Bramuglia, G.; Tiara, C. Una aproximación cinética y dinámica de metildopa en ratas con coartación aórtica mediante microdiálisis. Revista Argentina de Cardiología 1999, 67.

24. Schneider, S.; Ueberberg, S.; Korobeynikov, A.; Schechinger, W.; Schwanstecher, C.; Schwanstecher, M.; Klein, H.; Schirrmacher, E. Synthesis and evaluation of a glibenclamide glucose-conjugate: A potential new lead compound for substituted glibenclamide derivatives as islet imaging agents. Regulatory Peptides 2007, 139, 122-127, https://doi.org/10.1016/j.regpep.2006.11.004.

25. Figueroa-valverde, L.; Rosas, M.; Lopez, M.; Diaz, F.; Mateu, V.; Garcimarrero, A.; Ortiz, Y. Synthesis of a New Dioxaspiro[bicyclo[3.3.1]nonane-oxabicyclo[6.2.0]deca- 1(10),8-dien-4-one Derivative Using Some Chemical Strategies. Letters in Organic Chemistry 2010, 17.

26. Figueroa-Valverde, L.; Díaz-Cedillo, F.; García-Cervera, E.; Pool-Gomez, E.; Rosas-Nexticapa, M.; LópezRamos, M.; Vera-Escobedo, M. Design and synthesis of two triazonine- carbaldehyde derivatives using 
several chemical tools. Journal of Saudi Chemical Society 2018, 22, 183-197, https://doi.org/10.1016/j.jscs.2016.03.003.

27. Lauro, F.; Marcela, R.; Maria, L.; Francisco, D.; Alejandra, G.; Virginia, M.; Yazmin, O. Design and Synthesis of a new furan-steroid-propanone derivative using some chemical strategies. Steroids 2020, https://doi.org/10.1016/j.steroids.2020.108654.

28. Figueroa-Valverde, L.; Lopez-Ramos, M.; Diaz-Cedillo, F.; Rosas-Nexticapa, M.; Mateu-Armand, V.; Garcimarrero, A.; Ortiz, Y. Design and synthesis of new azetidine-steroid derivative with inotropic activity in a heart failure model. Vietnam Journal of Chemistry 2020, 58, https://doi.org/10.1002/vjch.201900131.

29. Xu, C.; Yuan, Y.; Yuan, R.; Fu, X. Enhanced photocatalytic performances of TiO 2-graphene hybrids on nitro-aromatics reduction to amino-aromatics. RSC Advances 2013, 3, 18002-18008, https://doi.org/10.1039/C3RA42579G.

30. Duan, Z.; Ma, G.; Zhang, W. Preparation of copper nanoparticles and catalytic properties for the reduction of aromatic nitro compounds. Korean Chemical Society 2012, 33, 4003-4006, http://dx.doi.org/10.5012/bkcs.2012.33.12.4003.

31. Eckert, H. Selective Reduction of the Nitro to the Amino Functional Group by means of the Phthalocyaninecobalt (i) Anion; Synthesis of N-Heterocycles and Alkaloids. Angewandte Chemie International Edition in English 1981, 20, https://doi.org/10.1002/anie.198102081.

32. Jacobs, W.; Heidelberger, M. The ferrous sulfate and ammonia method for the reduction of nitro to amino compounds. Journal of the American Chemical Society 1917, 39, 1435-1439, https://doi.org/10.1021/ja02252a017.

33. Verho, O.; Gustafson, K.; Nagendiran, A.; Tai, C.; Bäckvall, J. Mild and Selective Hydrogenation of Nitro Compounds using Palladium Nanoparticles Supported on Amino-Functionalized Mesocellular Foam. ChemCatChem 2014, 6, https://doi.org/10.1002/cctc.201402488.

34. Institute of Laboratory Animal, Resources Commission on Life Sciences, National Research Council. Guide for the Care and Use of Laboratory Animals. National Academies Press 1996; pp. 1-240.

35. Szkudelski, T. The mechanism of alloxan and streptozotocin action in B cells of the rat pancreas. Physiological Research 2001, 50, 536-546.

36. Gunton, J.; Delhanty, P.; Takahashi, S.; Baxter, R. Metformin Rapidly Increases Insulin Receptor Activation in Human Liver and Signals Preferentially through Insulin-Receptor Substrate-2. The Journal of Clinical Endocrinology \& amp; Metabolism 2003, 88, 1323-1332, https://doi.org/10.1210/jc.2002-021394.

37. Pompermayer, K.; Souza, D.; Lara, G.; Silveira, K.; Cassali, G.; Andrade, A.; Vieira, M. The ATP-sensitive potassium channel blocker glibenclamide prevents renal ischemia/reperfusion injury in rats Kidney International 2005, 67, 1785-1796, https://doi.org/10.1111/j.1523-1755.2005.00276.x. 